OPEN ACCESS

Edited by:

Shijun $\mathrm{Hu}$,

Soochow University, China

Reviewed by:

Walter Lee Murfee,

University of Florida, United States

Pu Chen,

Wuhan University, China

${ }^{*}$ Correspondence:

Yifei Li

liyfwcsh@scu.edu.cn $X i \operatorname{Ren}$

xiren@cmu.edu

Donghui Zhang

dongh.zhang@hubu.edu.cn

${ }^{t}$ These authors have contributed

equally to this work

Specialty section:

This article was submitted to

Stem Cell Research,

a section of the journal

Frontiers in Cell and Developmental

Biology

Received: 08 December 2020

Accepted: 29 March 2021

Published: 21 April 2021

Citation:

Meng $X$, Xing Y, Li J, Deng C, Li Y, Ren $X$ and Zhang $D$ (2021) Rebuilding

the Vascular Network: In vivo and in vitro Approaches.

Front. Cell Dev. Biol. 9:639299. doi: 10.3389/fcell.2021.639299

\section{Rebuilding the Vascular Network: In vivo and in vitro Approaches}

\author{
Xiangfu Meng ${ }^{1 \dagger}$, Yunhui Xing ${ }^{2 \dagger}$, Jiawen Li ${ }^{3 \dagger}$, Cechuan Deng ${ }^{4}$, Yifei Li ${ }^{3 *}, X_{i}$ Ren $^{2 *}$ and \\ Donghui Zhang ${ }^{\text {* }}$
}

' State Key Laboratory of Biocatalysis and Enzyme Engineering, School of Life Sciences, Hubei University, Wuhan, China, ${ }^{2}$ Department of Biomedical Engineering, Carnegie Mellon University, Pittsburgh, PA, United States, ${ }^{3}$ Key Laboratory of Birth Defects and Related Diseases of Women and Children of MOE, Department of Pediatrics, West China Second University Hospital, Sichuan University, Chengdu, China, ${ }^{4}$ Department of Obstetrics and Gynecology, West China Second University Hospital, Sichuan University, Chengdu, China

As the material transportation system of the human body, the vascular network carries the transportation of materials and nutrients. Currently, the construction of functional microvascular networks is an urgent requirement for the development of regenerative medicine and in vitro drug screening systems. How to construct organs with functional blood vessels is the focus and challenge of tissue engineering research. Here in this review article, we first introduced the basic characteristics of blood vessels in the body and the mechanism of angiogenesis in vivo, summarized the current methods of constructing tissue blood vessels in vitro and in vivo, and focused on comparing the functions, applications and advantages of constructing different types of vascular chips to generate blood vessels. Finally, the challenges and opportunities faced by the development of this field were discussed.

Keywords: vascular network formation, angiogenesis, cell therapy, decellularization, vessels on a chip

\section{INTRODUCTION}

The purpose of tissue engineering is to exploit engineering methods to overcome physiological or medical difficulties. Its main objective is to facilitate tissue or organ transplantation and scientific research constructing functional tissue models in vitro. After a long period of research and development, the technology of tissue engineering has achieved encouraging results and milestones. However, a significant challenge currently remains concerning how to generate a large volume $\left(>1 \mathrm{~cm}^{3}\right)$ of viable, functional tissue. At present, the main difficulty in constructing larger tissues is the inability to form a vascularized network in vitro to supply oxygen and nutrition; thus, the central areas of fabricated tissues without vascularization tend to undergo rapid necrosis. Thus, tissue engineering research has focused on how to generate functional vascular networks. Herein, we will introduce the current progress of vascular network construction, including histological and cellular characteristics, using in vivo and in vitro strategies for angiogenesis, and the potential clinical applications. This review will first introduce the basic characteristics of blood vessels in the body and the mechanisms involved in angiogenesis of blood vessels in vivo. The current methods of constructing tissue vessels in vitro are also described within this review, including the use of vascular chips, and the functions, applications, and advantages of the vessels generated by these different methods are compared and analyzed. 


\section{STRUCTURAL CHARACTERISTICS OF THE VASCULAR NETWORK}

\section{Histological and Cellular Fundamentals of Peripheral Vessels}

The peripheral vascular system (PVS) includes all the blood vessels that exist outside the heart. The classification of the PVS is described below. Arteries have larger calibers and a better capability to bear high perfusion pressure. When arteries reach a specific organ, they branch into smaller vessels. As a result, there are two main types of arteries in the body: (1) elastic arteries and (2) muscular arteries. Elastic arteries consist mainly of large arteries and directly connect to the heart (such as the aorta and pulmonary arteries) and present more elastic features. Muscle arteries mainly distribute as medium-sized vessels, and their walls primarily contain smooth muscle.

The arterioles are the main vessels present in different organs and present relatively limited amounts of elastic tissue. Capillaries are thin-walled blood vessels composed of a single layer of endothelial cells. Based on the histological and cellular characteristics of capillaries, the exchange of nutrients and metabolites is achieved mainly through diffusion. Unlike arteries, venous pressure is very low. The venous wall is thin and less flexible. The veins receive blood from capillaries to complete the circulation system.

The function and structure of each segment of the PVS depends on the organ which it supplies, varying across different tissues. Aside from capillaries, most blood vessels are made of three layers. The adventitia, or outer layer, is mainly composed of loose connective tissue, which provides structural support and maintains normal vessel shapes. The tunica media, or a middle layer, is composed of elastic and muscular tissue, which determines the internal diameter of the vessel. The inner layer is formed by a single layer of endothelial cells, which are surrounding by elastic fibers.

\section{Vessel Formation: Morphological Changes and Signaling Cascades}

There are several mechanisms involved in vessel formation and they are considered as different phases of the same biological process. Generally, vessel formation in an early development stage is defined as vasculogenesis, and describes the establishment of the first primitive vascular network. Next, angiogenesis follows the process of vasculogenesis, and consists of the formation of branches and vascular remodeling. Furthermore, angiogenesis is mainly used to describe vessel growth stemming from preexisting ones, and represents the main vessel formation process in adulthood. Typically, vessel formation may be divided into three steps: (1) vasculogenic assembly, (2) vessel sprouting, and (3) vascular remodeling.

During embryogenesis, the formation of new blood vessels is a de novo process. Angioblasts (mesoderm-derived endothelial precursors) differentiate into a primitive vascular labyrinth (vasculogenesis) (Uhrin, 2019). Within this process, angioblasts differentiate into endothelial cells (ECs), and the ECs are recruited to form vascular cords (Baldwin, 1996). Next, the vascular cords are further specified into hierarchically differentiated vessels of arteries, capillaries, and veins. To enable this process, several molecular signaling mechanisms have been implicated in the initial steps of vasculogenic assembly. Notch signaling is highly expressed in arteries, but poorly expressed in veins (Conway et al., 2001; Gridley, 2010). Blocking Notch signaling contributes to the genesis of more veins and disruption of arteries, which indicates that Notch signaling pathway is a key molecular mechanism in the induction of arteriogenesis. Furthermore, ephrin components are associated with Notch signaling: EphB2 is a target of Notch within arterial ECs and binds to EphB4 of venous ECs. Vascular endothelial growth factor (VEGF) is also a crucial factor that triggers arterial differentiation of ECs, and is a downstream component of the Hedgehog pathway (Kim et al., 2008). Moreover, transcription factors are also expressed by specific ECs. FOXC1 and FOXC2 drive the expression of arterial gene signatures under the guidance of VEGF and Notch signals (Hayashi and Kume, 2008). While COUP-TFII has been identified as a driving factor of venous cell fate. In addition, according to the different pressure loading profiles of the arterial and venous system, mechanical loading also contributes to the differentiation of specific vessels. Finally, the arterio-venous segregation is driven by VEGF-C.

A second process of vessel formation is defined as sprouting angiogenesis: there are three changes that define blood vessel morphology, sprouting, bridging, and intussusception, which is facilitated by two main types of cells: the tip cells and stalk cells (Conway et al., 2001). Essentially, the process could be described as (1) tip-stalk cell selection; (2) tip cell navigation and stalk cell proliferation; (3) branching coordination; (4) stalk elongation, tip cell fusion, and lumen formation; and (5) perfusion and vessel maturation. At the onset of sprouting, the tip cells secrete matrix metalloproteases (MMPs) such as MT-MMP1 to degrade basement membrane. Plasminogen activator inhibitor1 (PAI1) controls the amount of MMPs secreted to prevent over-degradation. Furthermore, the antiangiogenic molecules, angiostatin and endostatin, are also involved in this process and ensure the optimal sprouting direction. Additionally, detachment of mural cells is stimulated by angiopoietin-2 (ANG2) for tip cells movement in response to stimulation by VEGF. Next, VEGF/Notch signaling selects tip and stalk cells. Stalk cells express enriched Notch signaling and tip cells express low levels. Conversely, tip cells express higher levels of the Notch ligand DLL4. JAGGED1 (JAG1) is expressed in stalk cells and acts to inhibit DLL4 signal activity and maintain Notch activity. Filopodia guide tip cells by sensing attractive and repulsive cues. Filopodia formation is stimulated by $\mathrm{CDC} 42$ and by the endocytosis of EphB2/VEGFR2 receptors. ROBO4/UNC5B signaling promotes stabilization of the endothelial layer through inhibition of SRC. Notch-regulated ankyrin repeat protein (NRARP) and SIRT1 guide stalk cells stabilization. Both WNT and Notch pathways are also involved in stalk cell stabilization through interaction with NRARP and LEF1/B-CATENIN. Finally, the contraction of the cytoskeleton of ECs generates the vessel lumen. Besides ECs themselves, a few other cell types also make significant contributions to the angiogenesis process through their interaction with ECs. For example, macrophage 
mediates the tip cells fusion and branch anastomosis, including VE-cadherin controlling cell adhesion (Potente et al., 2011; Hong and Tian, 2020). Furthermore, pericytes, vessel associated multifunctional support cells, promote endothelial sprouting during angiogenesis and provide guidance by spatially restricting VEGF signaling (Eilken et al., 2017). Pericytes can also penetrate tissues prior to EC ingrowth and create a path enabling subsequent effective angiogenic invasion by ECs (Ozerdem and Stallcup, 2003; Rajantie et al., 2004; Eilken et al., 2017).

The final phase is vascular remodeling, transitioning from a primitive towards a more stabilized and mature vascular plexus, involving steps such as adoption of a quiescent endothelial phalanx phenotype, basement membrane deposition, pericyte coverage, and branch regression. Stalk cells are regulated by blood flow shear stress-induced KLF2 signals. The up-regulation of KLF2 controls the remodeling of the vasculature. High KLF2 signaling ensures the endothelial quiescence cells form patent vessels, while low KFL activity induces ECs apoptosis and regression to terminate a vessel. The recruitment of pericytes is guided by platelet-derived growth factor receptor (PDGFR) B, S1PR1, EphB2, and Notch3 signaling. The process of pericyte coverage and acquisition of an endothelial phalanx phenotype is the typical sign of vessel maturation. Further, hypoxic conditions trigger the expression of HIF- $\alpha$, leading to the over-expression of sVEGFR1 and VE-cadherin to force neoangiogenesis so as to improve oxygen perfusion.

Given the extensive interplay of ECs, pericytes and macrophages at different stages along blood vessel formation, recapitulating the spatial and temporal interaction of this multicell-lineage system is of critical importance for enabling effective vasculogenesis and angiogenesis in tissue-engineered models. All the molecular biological processes were summarized in Figure 1.

\section{INDUCING VASCULAR REGENERATION IN VIVO}

\section{Growth Factors Stimulating Angiogenesis}

From an angiogenesis perspective, growth factors play critical roles in directing cells to initiate and maintain angiogenesis, since they are responsible for transmitting signals between cells and between cells and their microenvironment (Elaimy and Mercurio, 2018; Omorphos et al., 2021). Several growth factors have been widely studied and proven to be effective in promoting vascular regeneration, including VEGF, basic fibroblast growth factor (bFGF), placental growth factor (PLGF) and platelet-derived growth factor-BB (PDGF-BB) (Elaimy and Mercurio, 2018; Hao et al., 2018; Kant and Coulombe, 2018).

Despite the therapeutic potential of growth factors in promoting tissue regeneration, their clinical application is hindered by their limited stability and systemic side effects in vivo. The stability of growth factors can be enhanced by their incorporation into polymers to form a delivery system, which extends the in vivo half-life while maintaining bioactivity (Wang et al., 2017; Caballero Aguilar et al., 2019). In addition, delivery systems are able to provide spatial control of growth factor release, since they should remain at the target location long enough to induce a cellular response. After incorporation into hydrogel systems, growth factors, such as VEGF and bFGF showed improved ability to promote angiogenesis, long-term stability, and spatial localization in vivo compared to bolus injection or delivery in the aqueous solution of polymer (Adibfar et al., 2018; Shamloo et al., 2018).

\section{Delivery Strategies for Growth Factors}

Three main methods have been applied for delivering angiogenic growth factors: (1) physical entrapment; (2) immobilization by covalent conjugation; and (3) the use of biocompatible micro/nano-particles. Physical entrapment can be achieved either by mixing growth factors with polymers before gelation or by physical absorption after polymer scaffold manufacturing (Tayalia and Mooney, 2009). By incubating with growth factors, such as VEGF, PDGF-BB, and transforming growth factor beta (TGF- $\beta 1$ ), an alginate-sulfate hydrogel preparation triggered the formation of mature vascular structure (Freeman and Cohen, 2009; Sarker et al., 2019). Neovascularization responses may also be generated with hyaluronan hydrogel by mixing VEGF, bFGF, or KGF with polymers before gelation (Peattie et al., 2006; Pike et al., 2006; Graça et al., 2020). In order to achieve higher stability and prolonged release, growth factors can also be immobilized into polymers by covalent bonding. This usually requires chemical or enzymatic reactions between the growth factors and polymer scaffolds. For example, 1-ethyl-3-(3-dimethylaminopropyl)-carbodiimide hydrochloride (EDC) was used to covalently immobilize VEGF and angiopoietin-1 onto collagen scaffolds with controlled angiogenic bioactivities (Chiu and Radisic, 2010; Enriquez-Ochoa et al., 2020). In addition, growth factors can also be encapsulated or conjugated with biocompatible micro/nanoparticles, which allows precise control of the growth factor release rate and cellular uptake efficiency by fine-tuning the particle size and the surface-to-volume ratio (Tayalia and Mooney, 2009; Oduk et al., 2018). Likewise, the release of growth factors can be prolonged in the local microenvironment, leading to improved cellular responses and stability (Chen et al., 2010). It has been reported that following treatment with nanoparticle-encapsulated VEGF, vascularization and angiogenenic responses were achieved in the mouse hindlimb ischemia and rat myocardial infarction models (Golub et al., 2010; Oduk et al., 2018).

Since proteins generally lack stability in vivo, introducing growth factors by DNA transfer could provide sustained support for vascularization or angiogenesis. The delivery of VEGF gene using direct injection of naked plasmids or adeno-associated viruses (AAVs) has produced positive results in the activation of angiogenic genes and vascular regeneration, in critical limb ischemia and myocardial infarction models (Schwarz et al., 2000; Boden et al., 2016; Liu et al., 2017; Samatoshenkov et al., 2020). Endothelial progenitor cells (EPCs) with adenovirus transduction of the VEGF gene were tested in a mouse limb ischemia model and the implanted cells facilitated the neovascularization of the impaired region (Iwaguro et al., 2002). 


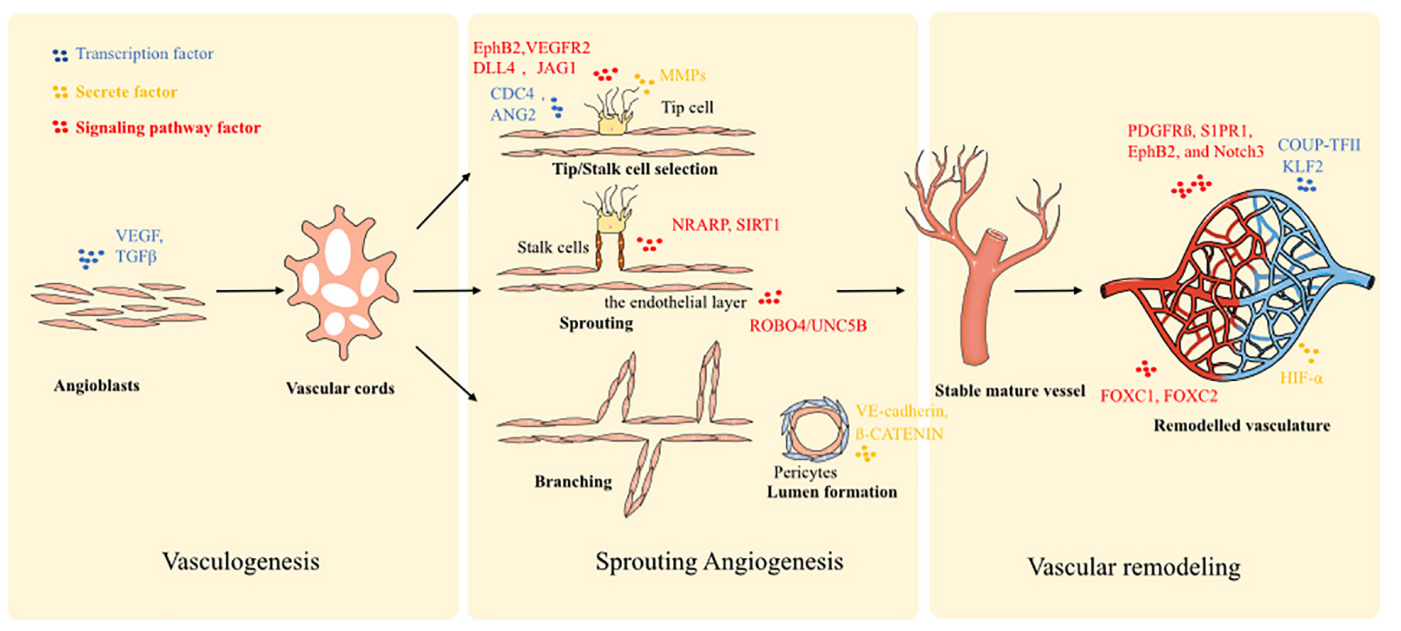

FIGURE 1 | The major molecular regulators in vasculogenesis, angiogenesis, and vascular remodeling.

Similarly, adipose stromal cells are able to serve as a vector for growth factor delivery because of the angiogenic growth factors they secrete, and have demonstrated remarkable angiogenic potential in a limb ischemia model (Rehman et al., 2004; Zhao et al., 2017). However, with DNA transfer it is difficult to control the exact dosage, and risk of mutagenesis from genome integration is also an important issue that needs to be taken into consideration. Compared to DNA delivery, RNA is an attractive alternative because of its ability to induce an exogenous transient expression of growth factors without mutagenesis risk (Lui et al., 2014). The mouse myocardial infarction model was used to test the transplantation of modified RNA encoding VEGF by intramyocardial injection. Injection of the modified RNA increased capillary density and reduced the area of infarction while inducing the differentiation of epicardial progenitor cells towards endovascular cells (Zangi et al., 2013).

\section{Non-coding RNAs for Angiogenesis in vivo}

Non-coding RNAs, which target mRNAs in a sequence-specific manner, contribute to the regulation of angiogenesis. miRNAs are a type of small endogenous non-coding RNA, which have been a focus of research for over a decade. A series of miRNAs have been shown to have pro- and anti-angiogenic characteristics. MiR-199a, miR-150, miR-145, and miR-153 interact with VEGF signaling, while miR-134, miR-153-3p, and miR-137 regulate Notch signaling activity, and are all involved in modulating angiogenesis (Zhao et al., 2020). MiR-320a and miR-27b have been administered in a preclinical study to re-establish neovascularization in retinopathy (Zampetaki et al., 2016). MiR-424 and miR-210 have been shown to have proangiogenic features in myocardial infarction (Hu et al., 2010), while miR-92 exerts antiangiogenic activity (Bonauer et al., 2009). Furthermore, several miRNAs (including miR-1, miR-133, and miR-126) have been used to inhibit angiogenesis as cancer therapy (Nohata et al., 2012).
In recent years, long non-coding (Lnc)-RNAs have also been discovered and their biological roles have been demonstrated more clearly. Lnc-SNHG1, H19, MIAT, ZFAS1, MEG8, MALAT1, NEAT1, and TUG1 have been identified for their ability to promote angiogenesis via targeting VEGF expression (Zhao et al., 2017; Hou et al., 2018; Long et al., 2018; Smith et al., 2018; Wang et al., 2018; Zhou et al., 2019; Barth et al., 2020; Li et al., 2020; Sui et al., 2020). Several in vivo delivery studies have confirmed their functional benefit in the prognosis of ischemic injury, especially of the heart and brain. Moreover, lnc-DIGIT, HIF1A, and XIST, targeting the Notch and DLL4 genes, modulate vascular network remodeling (Hayashi and Kume, 2008; Li et al., 2017; Miao et al., 2018; Tetzlaff and Fischer, 2018).

To deliver the non-coding RNAs in vivo, two common strategies are typically used: viral and non-viral introduction (Huang et al., 2020). For virus-based approaches, an AAV has been approved by the United States Federal Drug Administration for oligonucleotide delivery (Wang et al., 2019). Taking advantage of the AAV system, non-coding RNA inhibition and overexpression can be achieved by specific tissue infection based on different serotypes. Besides, adenovirus and lentivirus-based approaches have also been used to transfect animals in in vivo research studies. For the non-viral introduction, liposomes, nanoparticles, and hydrogels have been used to deliver non-coding RNAs for promoting vascular tissue regeneration ( $\mathrm{Li}$ et al., 2018). Furthermore, chemical modifications of the oligonucleotide has been explored to further improve their in vivo stability and bioactivity, and include cholesterol modification, methoxyethyl modification, locked nucleic acid (LNA), and antagomirs strategies (Duygu et al., 2019).

\section{CELL THERAPY IN VIVO}

Besides biomolecular delivery, cell therapy is considered an alternative method for boosting angiogenesis. There are two 
main strategies for implanting cells to target tissues, one is the direct cell delivery without material support (Hur et al., 2004), and the other involves embedding cells into a specific biomaterial matrix (Blache and Ehrbar, 2018), such as hydrogel, to generate a compound construct. EPCs are considered to possess the most appropriate features suitable for neovascularization in ischemia, as they reside in the bone marrow and retain the ability for self-renewal and transformation into mature ECs (Ingram et al., 2005; Bogoslovsky et al., 2010; Raval and Losordo, 2013). Thus, this type of cell source has been applied in several preclinical studies of functional vascular regeneration, including peripheral ischemia, myocardial infraction (NCT02174939 and NCT03216733) and ischemic cerebral stroke (NCT01289795, NCT01468064, NCT02157896, NCT02605707, and NCT02980354). The studies by Jeevanantham et al. (2012) and Erbs et al. (2007) demonstrate positive results for cell therapy after myocardial infraction in promoting heart function and rebuilding coronal microvascular circulation. Although no evidence has been presented indicating that EPCs can differentiate into other cell types beyond ECs in the heart, in the nervous system, EPCs can integrate into the vascular endothelium in ischemic areas and stimulate neurogenesis (Bogoslovsky et al., 2010).

The three-dimensional (3D) matrix of hydrogel has desired permeability and can effectively enable the diffusion of nutrients and metabolic wastes to the embedded cells, thereby supporting their survival and physiological functions, and has been extensively used for cell encapsulation and delivery (Schmidt et al., 2008). Hydrogel materials have become valuable 3D scaffolds for vascular engineering since they share many features with the natural extracellular matrix (ECM), including high water content and viscoelastic properties. Many hydrogel materials also offers tunable degradability, and can be gradually replaced by the host's ECM as the implanted tissues constructs mature in vivo (Langhans, 2018). Typically, the strategy includes four steps: (1) selection of cell sources: somatic cells, adult progenitor and stem cells, and pluripotent stem cells (PSCs) can be used to produce ECs; (2) establishment of hydrogel scaffolds: natural polymers, including collagen, poly(ethylene glycol) (PEG), gelatin methacrylate (GelMA), and synthetic polymers (including polylactic-co-glycolic acid) (PLGA), polycaprolactone (PCL), poly-L-lactic acid (PLLA), glycosaminoglycans (GAGs), hyaluronic acid (HA), and arginine-glycine-aspartic acid (RGD), have been used to manufacture hydrogel matrices for EC embedding and building micro-vessel systems (Khetan and Burdick, 2010; Chwalek et al., 2014; Blache and Ehrbar, 2018). (3) Compound functional graft building: the combination of scaffold, cells, growth factors, and mechanical stimuli recreates a functional microenvironment that stimulates tissue organization into an integrated engineered graft. (4) Graft implantation: the functional graft can be delivered in either in micro $(10 \mu \mathrm{m})$ and nano $(10 \mathrm{~nm})$ molecules of gels for skin wound repair and osteogenesis in bone loss (Shen et al., 2016; Alarçin et al., 2018). Furthermore, injectable hydrogels can be used for intra-vascular delivery, especially in myocardial infarction (Yang et al., 2018).

\section{ENGINEERED RECAPITULATION OF THE VASCULAR CIRCULATION IN VITRO}

\section{Vascular Regeneration From Decellularized Matrix}

The vasculature of native organs has complex spatial architecture that is essential for the organ-specific functions (Theocharis et al., 2016; Gilpin and Yang, 2017). The decellularized organ ECM also offers preserved essential ECM composition for supporting vessel formation, and serves as a reservoir for bioactive cues, such as growth factors and cell-adhesive mediators (Rhodes and Simons, 2007; Chan and Leong, 2008). Following decellularization, the porcine dermis showed retention of ECM proteins and expression of inherent growth factors, such as VEGF, TGF $\beta$, and FGF, which have bioactive potential to stimulate vascular regeneration (Hoganson et al., 2010). The closed circulatory circuit within an organ is composed of multiple types of blood vessels with diverse functions, which are supported by the surrounding ECM (Thottappillil and Nair, 2015). Via decellularization, it is possible to preserve the composition and the overall architecture of specific blood vessel types and to achieve organ-specific vascular regeneration (Rhodes and Simons, 2007; Thottappillil and Nair, 2015). For example, sinusoids are capillaries that exhibit an incomplete basal membrane and widely exist in the adrenal glands, liver, spleen, and bone marrow (Augustin and Koh, 2017). In the decellularized human liver, the sinusoid structures are preserved and allow the migration of LX2 cells during recellularization (Mazza et al., 2015).

The ECM scaffolds used for regenerating large-diameter vascular conduit can be obtained from both decellularized vascular and non-vascular structures. The decellularized ureter and umbilical artery are capable of supporting endothelialization, leading to durable blood vessel formation in in vivo animal models (Narita et al., 2008; Gui et al., 2009). Recellularization for vascular scaffolds can be accomplished either in vivo by recruiting host's cells following implantation or by in vitro culture with seeded cells (Yow et al., 2006). Following implantation, the decellularized allograft matrices demonstrated recellularization by recruiting host cells in vivo for ovine vessel and rat aortic conduit reconstructions (Ketchedjian et al., 2005; Assmann et al., 2013). The sources for in vitro recellularization can be mature vascular cells, such as ECs or smooth muscle cells, and EPCs (Zhang et al., 2007). For example, porcine iliac arteries can be decellularized and seeded with EPCs before transplantation, which allowed improved patency rates in vivo (Kaushal et al., 2001). However, efficient regeneration of complex microvascular structures, especially recapitulating their organotypic anatomy and functionality, remains challenging.

As an effort to address these challenges, advances in whole-organ perfusion decellularization in the past decade provide a convenient approach for producing organ-specific, acellular vascular bed allowing access to both macrovascular and microvascular compartments throughout the entire organ. For example, to rebuild the gas exchange function and attain vascularization, rat lungs were decellularized and seeded with 
ECs and epithelial cells or adipose-derived stromal cells within a bioreactor, which simulated a biomimetic culture conditions. Following orthotopic transplantation, the mature vascularized lung constructs was capable of providing gas exchange function in vivo (Ott et al., 2010; Doi et al., 2017). For the recellularization of a liver graft, hepatocytes and ECs were used to reconstruct the vasculature in the decellularized liver matrix (Uygun et al., 2010). Using perfusion recellularization, the embryonic stem cells or iPSC-derived ECs can be efficiently retained in the decellularized kidney scaffold, resulting in a uniform distribution in the vascular network and in glomerular capillaries, together with site-specific EC specialization (Bonandrini et al., 2014; Ciampi et al., 2019).

\section{Mimicking Angiogenesis in vitro}

Compared to angiogenesis in vivo, models simulating angiogenesis in vitro can precisely control each component of vascular development, imitate the complex microenvironment and required factors in the body, with high repeatability. In current studies, in vitro vascular research usually uses differentiated ECs or adult EC lines and another type of cells (such as fibroblasts/mesenchymal cells/parenchymal cells, and even tumor cells) to be cultured under controlled 3D conditions. This creates a defined culture system for studying the effects of certain variables on angiogenesis. Two-dimensional (2D) in vitro models can be used to study the behavior of ECs, such as migration and proliferation; however, because $2 \mathrm{D}$ models lack the more physiological 3D environment, they cannot reflect the contribution of numerous typical characteristics of ECs, such as lumen formation and differentiation into tip and stalk cells. Therefore, constructing a 3D vascular model is particularly helpful for studying vascular tissue behavior with reproducible conditions of morphology and signals. Moreover, through reasonable engineering design, a high-throughput angiogenesis model has been developed, which facilitates screening of angiogenesis modulators.

Blood vessels are organs of luminal structure with essential transport and perfusion functions. Therefore, how to realize the perfusion and circulation function is a key task to accomplish for engineered vascular network in vitro. Tissue engineering methods for constructing 3D blood vessels in vitro mainly include self-organized cell sheets, 3D printed blood vessel networks and blood vessel chips (Sarker et al., 2018). In the self-organization approach, the growth and developmental process of the vascular system is stimulated, causing the EC to spontaneously form blood vessels in the hydrogel with native-like morphology and function. However, due to the randomness of self-organization, it remains difficult to perform fluid infusion. Although 3D printing blood vessels is convenient and automated, it is challenged by the difficulty to remove the hollow channels where the materials and blood vessel cells are fused, and the low spatial resolution.

Jeon et al. (2014) combined ECs with the ECM, and observed the generation of microvascular networks, in which ECs began to aggregate into a solid tube-like shape, with buds extending outward while responding to the effects of native-like growth factor combination of VEGF, TGF $\beta 1$, and Ang1. Belair et al. (2015) implanted iPSC-ECs and lung fibroblasts into fibrin gels within microfluidic devices. At the beginning of the culture, iPSC-ECs showed budding, migration, and invasion behavior, and were able to respond to fluid stimulation by extending in the direction of the fluid flow and forming perfusable lumens (Belair et al., 2015). van Duinen et al. (2017) developed a model of 96 individually addressable, 3D microvessels in a standardized microfluidic platform. It allows simultaneously analysis of the effects of different ECM/medium/cytokines (VEGF, TNF $\alpha$, and IL-1 $\beta$ ) on the barrier function of the engineered microvessels (van Duinen et al., 2017). The same group later refined this design and developed a more standardized high-throughput culture platform integrated into a 384-well plate, which formed 40 repeating units of three microfluidic channels. It can detect the effects of multiple factors and shows promise in application to screen vascular-related drugs (van Duinen et al., 2019). Kim et al. (2015) proposed a quantitative microfluidic angiogenesis screening platform (QMAS) that can monitor and quantify cell behavior from treatment with various drug concentrations, such as morphological changes, EC viability, and angiogenic bud formation. The platform has 14 connected chambers, with medium flowing through the gaps between each chamber to achieve a drug concentration gradient (Kim et al., 2015).

\section{Establishing Different Types of Microvessels on a Chip}

At present, there are several different constructions and design strategies that have generated blood vessel chips. Generally, there are five types of vessel chips available as in vitro models: (1) microfluidic membrane: a microfluidic device incorporating a mechanically stretchable membrane that can capture the organ-level function of vascular and epithelial interfaces; (2) microfluidic scaffolds: a standalone microfluidic network that can be fabricated using a synthetic polymeric elastomer serving as a scaffold for the construction of vascularized functional tissues; (3) microfluidic hydrogels: consisting of hydrogels with built-in microchannels, that offer an alternative method to model tissue interfaces; (4) self-assembled microvasculature: which establish proper connections to microchannels — such a self-assembled microvasculature can be perfused with a microfluidic circuit; (5) open-well design: uses preformed parenchymal tissues, such as tumor spheroids, that can be inserted on a preformed vascular bed in a multistep seeding approach - the versatility of this platform is that it allows potential integration of the microvasculature with various models of dense solid tissues (Zhang et al., 2018).

Initial efforts focusing on building microfluidic chip devices with only vascular structures, primarily for validating the vascular functions in response to fluid flow. To date, several cell sources have been explored to generate microvascular networks, including colony-forming cell-derived ECs isolated from the cord blood, human dermal microvascular ECs, kidney peritubular microvascular ECs and HUVECs. These artificial tissues model the formation of a vascular barrier with perivascular interaction, vascular sprouting, a basement membrane, and ECM formation, and cytokine responses. Elevated gene expression of VCAM1, E-selectin, ICAM1, and leukocyte recruitment in response to TNF-a stimulation allows modeling of vascular dysfunction due to sepsis and inflammation. Furthermore, several molecular tests could be performed to evaluate the inhibitory effects 

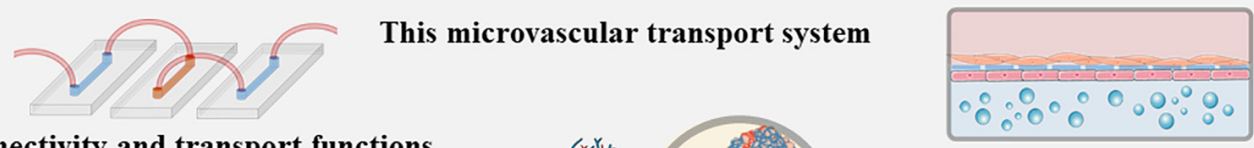

Connectivity and transport functions

1.The microvascular transport system.(Schimek, Busek et al. 2013)

2. Coculture multiple cell types in a microfluidic multi-organ chip.(Materne, Maschmeyer et al. 2015) 3. Multisensor-integrated organs-on-chips platform .(Zhang, Aleman et al. 2017)

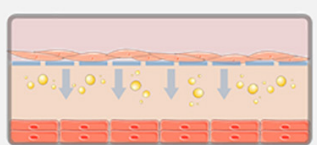

Barrier and secretion

1. BBBs-on-chips for the prediction of clearance of drugs. ((Booth and Kim 2014, van der Helm, van der Meer et al. 2016)

2.Permeability assay system for cerebral microvasculature.(Yeon, Na et al. 2012)

3. 3D BBB model for change of Rho kinase and ZO-1

expression in oxidative stress.(Bray, Binner et al. 2015)
The Specific organ interface

1.A pulmonary-arterial-hypertension ( $\mathrm{PAH}$ ) on a chip.(Al-Hilal, Keshavarz et al. 2020)

2. liver-on-a-chip to study steatosis pathogenesis and metabolism status.(Lasli, Kim et al. 2019)

3. Bile duct-on-a-chip.(Du, Khandekar et al. 2020)

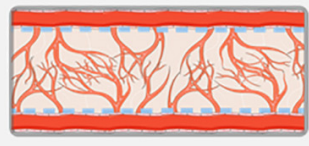

Mimic angiogenesis in vitro

1.The effects of similar growth factors in 3D functional microvascular networks.(Jeon, Bersini et al. 2014)

2.The synergistic signal of FGF-2 and VEGF .(Belair, Whisler et al. 2015)

3.High-throughput microvascular networks for screening inflammatory factors and vascular-related drugs.(van Duinen, Zhu et al. 2019)

4. An pathological organotypic eye-on-a-chip model.(Chung, Lee et al. 2018)

FIGURE 2 | The major mimic strategies of vessels on a Chip.

on angiogenesis. Yasotharan et al. (2015) have built vessel chips using arteries from mice based on a microfluidic platform, and tested the calcium flux and dose-dependent vasoconstriction in response to phenylephrine, in the presence or absence of nifedipine.

Moving to engineering vascularized complex tissues, the blood-brain barrier (BBB) model has been generated by a hierarchical combination of ECs, neurons, and astrocytes based on a microfluidic platform (Andjelkovic et al., 2020). The sources of ECs for this purpose can be HUVECs, and primary brainderived microvascular ECs. The BBB tissue models act as assays of drug activity, allowing evaluation of the flow, structure, and metabolic characteristics of brain vessels. Moreover, the incorporation of microvascular network is also important for studying tumor tissue biology as angiogenesis is essential for tumor growth. Thus, co-culture of various cancer cells with perfusable microvasculature allows generation of a virtual tumor tissue and provides a platform to observe tumor growth characteristics, screen drugs, and assess the efficacy of radiation therapy (Dijkstra et al., 2018). All the above information has been summarized in Figure 2.

\section{PRACTICAL AND CLINICAL APPLICATIONS OF VESSELS ON A CHIP}

\section{Drug Testing}

Preclinical drug screening is mainly performed using animal models. Although of great value, animal responses to drugs may show differences in terms of toxic doses and drug metabolism compared to human patients. Disease models tissue-engineered with patient cells can be used to accurately predict drug responses on tissue or even organ scales. Many current in vitro disease models often contain only the organ parenchymal cells without vascular support; thus, lack the ability to investigate the transport and metabolism of drugs in the vascular system (Fernandez et al., 2016). Compared with animal models and 2D experimental platforms, microvascular chips can conduct more detailed experiments on factors affecting vascular formation and have greater potential for use in vascular disease models to study pathological events and develop drug screening platforms. Besides, the microvascular chip systems have already made into commercial application beyond laboratory, focusing on highthroughput drug screening, precise diagnosis, disease modeling, and targeted therapy verification, which provide essential models for clinical management of cardiovascular diseases with opportunities of new discoveries (Portillo-Lara et al., 2019; Savoji et al., 2019).

In general, drug testing focuses on three aspects: (1) effects of drugs on vascular function. Microvascular networks and artery tissue models provide a platform to test drug effects on vessel growth and contraction, such as inhibitors of Rho kinase (Y27633), tyrosine phosphorylation (genistein), SRC kinase (PP2), and nitric oxide (L-NAME) (Ribas et al., 2016). (2) Molecules for blood barrier transportation. BBB and bloodretina barriers are always impediments for drug transportation and cellular translocation to particular tissues of interest to reach a proper therapeutic dose. Booth and Kim (2012) published their $\mu \mathrm{BBB}$ model, and demonstrated that co-culture with astrocytes resulted in an improved barrier functionality. Further, 
they showed that permeability coefficients in their model under dynamic conditions correlated well with in vivo brain/plasma ratios, demonstrating the potential of this model to predict drug clearance by the BBB (Booth and Kim, 2014; van der Helm et al., 2016). Cho et al. (2015) published a 3D BBB model, with the ability to record transmigration of neutrophils across the endothelial barrier and through the side channels, which was used to study ischemia by exposing the endothelium to low oxygen and low glucose levels and subsequently allowing reoxygenation to normal conditions. Formation of reactive oxygen species and the activation of Rho kinases as a result of oxidative stress was confirmed, as well as a decrease in tight junction ZO-1 expression. These in vitro culture models (van der Helm et al., 2016) have been used in combination with animal models as a supplementary testing platform, as at this stage the in vitro platforms alone are not yet suitable to reproduce all functional activities. (3) Chemical medication screening. Coculture of cancer cells and the permeable microvascular network could induce tumor tissue growth in vitro (Bray et al., 2015), and offers the possibility for screening of chemotherapeutic agents. Drug screening has been performed to evaluate the inhibition efficacy on tumor growth and on the associated vasculature, by agents such as bortezomib, vincristine, mitomycin C, gemcitabine, vorinostat, tamoxifen, linifanib, axitinib, and sorafenib, pazopanib, oxaliplatin, folinic acid (leucovorin), and 5-fluorouracil (Zhang et al., 2018).

\section{Disease Modeling}

Modeling a disease using patient-derived cells provides insight into the underlying pathology. Importantly, this approach provides huge advantages over the use of animal models, as animal models often cannot completely reproduce the physiological responses of human tissues (Cochrane et al., 2019).

An organotypic eye-on-a-chip model has been described, which mimics the retinal pigment epithelium (RPE)-choroid complex in vitro. This model consists of a RPE monolayer and adjacent permeable blood vessel network, which supports the barrier function of the outer blood-retina barrier (oBRB). The intact barrier function of the RPE-choroid complex is reconstituted while maintaining important structural features. Further, this model can successfully mimic the pathogenesis of the choroidal neovascularization $(\mathrm{CNV})$. The alleviation of the pathological angiogenesis mechanisms can be modeled with bevacizumab, a clinical drug used in $\mathrm{CNV}$ treatment (Chung et al., 2018), utilizing blood outgrowth ECs (BOECs) as a diseasespecific primary cell source to analyze vascular inflammation and thrombosis in vascular organ-chips or "vessel-chips" (Mathur et al., 2019). Similar concepts have been applied to other organ systems. Al-Hilal et al. (2020) reported a pulmonary-arterialhypertension $(\mathrm{PAH})$ model on a chip to elicit arterial remodeling under $\mathrm{PAH}$. The authors fabricated a microfluidic device to emulate the luminal, intimal, medial, adventitial, and perivascular layers of a pulmonary artery. Three types of pulmonary arterial cells (PACs), endothelial, smooth muscle, and adventitial cells were seeded to form the model. Moreover, Lasli et al. used the human hepatocellular carcinoma (HepG2) cell line and HUVECs as spheroid cultures to establish a "liver-on-a-chip" model to study steatosis pathogenesis and metabolism status (Lasli et al.,
2019). In addition, Du et al. (2020) attempted to build a "bile duct-on-a-chip" to achieve organ-level function as a specific vessel device to evaluate bile duct pathophysiological processes.

Moreover, disease models have also been built to study the blood vessels themselves by examining endothelial dysfunction. TNF- $\alpha$ stimulation has been used to explore the biological procedure of thrombus formation as a mechanical cue. Further, ECs binding of $\mathrm{T}$ cells and neutrophil extravasation has been used to study the activation of endothelial inflammation. However, there is no suitable model to evaluate the features of Kawasaki disease. Thus, vessels chips may provide an opportunity to approach the pathogenesis of coronary lesions of Kawasaki disease. Furthermore, this platform may contributes to understanding mechanisms that promote thrombus formation, plaque geometry, and the high permeability observed in the atherosclerotic endothelium.

\section{Tissue Regeneration and Repair}

The limitations of organ transplantation due to insufficient organ supply have given rise to the development of regenerative medicine. Its main purpose is to replace missing or damaged tissues with materials and tissue-specific cells and their various combinations to promote structural and functional healing. Currently, only a few engineered tissues (skin, cartilage, and bladder) have reached clinical success, while biomaterials designed to replace more complex organs have not been commercialized because, unlike engineered skin, cartilage, or bladder tissue, cell viability and the optimal function of the construct cannot be maintained by diffusion alone, and oxygen and nutrients necessary for survival and organ integration cannot be effectively supplied following transplantation. Therefore, the generation of functional vasculature is critical to the clinical success of engineering and construction of organs (Bae et al., 2012).

The human body contains a rich blood vessel network, which is mainly used for supplying oxygen and nutrients. Therefore, for regenerative tissue culture models, a multi-organ chip system containing a blood vessel network chip is physiologically relevant. Schimek et al. (2013) established a human cardiovascular on a chip-based system, with the microvascular system co-cultured with skin and liver tissue, and demonstrated the ability of the microvascular chip to promote the survival of other tissues. Materne et al. (2015) proposed a protocol to co-culture multiple cell types in a microfluidic multi-organ chip, and successfully constructed a microenvironment of skin tissue and liver tissue and blood vessels, enabling the a circulation network. The development trend of organ chips is that of multi-organ combined chips; thus, researchers have attempted to integrate multiple types of chips into "body-chips." Zhang et al. (2017) built an easy-to-use modular, sense-based, multi-organ platform, whereby multiple organoid models (human cardiac organoids and vascular organoid, and human liver organoids) are connected by micro-organ chip technology, which can systematically study and analyze the ability of multiple organ interactions, with the advantages of continuous, dynamic, and real-time monitoring (Zhang et al., 2017).

Engineering a functional alveolar-capillary interface (lung), large functional myocardial tissue with suppling vessels tissue 
(heart), functional hepatic tissue combining hepatocytes and the bile duct (liver), functional renal tissue comprising permeability and filtering features (kidney) is the main goal for organ tissue construction from a regenerative perspective. Furthermore, mimicking the 3D arterial architecture, vascularized skin would also be more helpful for wound repair. Thus, the combination of functional artificial tissue with a vascularized network is a critical, desired objective for regenerative medicine. The establishment of blood vessels in different organs and different types of "organ on the chip" is summarized in Table 1.

\section{DISCUSSION AND FURTHER CHALLENGES}

Although rapid progress has been made in the field of vascular tissue engineering in the past decade, the lack of functional vasculature has been widely regarded as one of the main obstacles hindering the effective reproduction of in vivo physiology. So far, the method of vascular reconstruction using acellular matrix in the body is mainly aimed at the reconstruction of large blood vessels. The real perfusion function of the whole blood vessel network can only be achieved following transplantation into the body and anastomosis with the host blood vessels. Chips have many recognized advantages as a convenient in vitro model of organ function and disease. Therefore, in vitro engineered pre-vascularization followed by embedding other organ models into the pre-established capillary bed, can be regarded as a way to realize the co-cultivation of microvascular chips and other organs.

\section{Bottleneck of Building Tissue-Engineered Blood Vessels}

Building a functional vascular network has long been recognized as a major challenge in tissue engineering. Although we have now developed various types of vascular chips and printed vascular networks, there remains a lack of effective methods for regulating vascular network conformation and vascular scale, as well as a lack of commercially available models that are capable of supporting physiological perfusion and implantation. There is an unmet need to identify proper sources of patient-derived cells to be applied in organ-onchip models to increase our mechanistic understanding of diseases and to assess the efficacy of drugs. The interactions between blood flow, vessel architecture, cells, and parenchymal tissues vary drastically from organ to organ. These differences largely arise from the structural, compositional and functional differences of the vasculature in different organs. The organspecific origin of endothelial cells can have a profound effect on the biological activity. Many commonly used generic ECs, such as HUVECs, lack the characteristics presented by microvascular endothelial cells, which is an important feature for model systems. Thus, the choice of ECs will depend on the specific organ model and the corresponding parenchymal tissues. In the method of using acellular matrix and whole organ perfusion to build vascular network, the cell sources are always limited within a few cellular types, which is probably insufficient to establish functional, organotypic circulation network. Advances in targeted differentiation of stem cells and primary tissue isolation techniques will help us develop more organ-specific ECs (Lin et al., 2019). Taking advantage of these innovations, we expect continuing progresses toward engineering organ-specific vascular systems for improved understanding of the physiological and molecular mechanisms of organ and tissue formation.

The application of acellular matrix for rebuilding vascular network is superior compared to other synthetic matrices, but it remains difficult to fully recapitulate the native growth factor environment. The material used for the blood vessel chip should also consider the characters of material to support cellular growth in tunnel formation. Besides natural scaffolds, polydimethylsiloxane (PDMS) is the one of most widely used synthetic materials, which demonstrates the features of insulation, non-conductivity, resistance to leakage, good biocompatibility, easy oxygen permeability, and good optical properties. However, PDMS is difficult to be used for regeneration and transplantation applications due to its non-degradability. With the development of new materials, acellular matrices, and artificial polymers should be designed in combination with each other to facilitate the building of functional vascular network (Zhang et al., 2018).

Materials for construction of chips, cellular fidelity, multiplexing, fluid handling, scalable production, and validation of organ-on-a-chip devices are all areas requiring further study (Zhang et al., 2018). Material modification techniques should be developed to enable the modulation of material biocompatibility as well as their function on proliferation and differentiation. In addition, materials to be in contact with blood, there has always been a challenge of potential thrombosis, thus material modifications that reduce thrombogenicity is an area of extensive research for future development of vascular interfaces (Greco Song et al., 2018). In addition, computational modeling that enables the design of physiologic network architecture, including channel size, hierarchical structure, flow rate control are is desired (Chandra and Atala, 2019).

\section{Cross-Cooperation Across Research Fields}

To build vascular network mentioned in this article is a field that requires interdisciplinary methods, knowledge, and technologies in biotechnology, tissue engineering, vascular biology, biomaterials, cell engineering, and stem cell biology (Li et al., 2014). In order to achieve effective and functional vascularization of biological materials, it is necessary to make the combination and synchronization of several factors that effectively characterize tissue vascularization in vitro, incorporating the inherent characteristics of biological materials and adapting to scaffolds. The biological concerns include how to control vascular stimulation by pro-angiogenic molecules, appropriate culture conditions, and fluid shear stressor. When these factors are integrated on the chip, they may affect the 
TABLE 1 | Build the blood vessels in different organ and different type of "organ on the chip."

\begin{tabular}{|c|c|c|c|c|}
\hline Chip type & Cell types & Hydrogel & Features & Reference \\
\hline $\begin{array}{l}\text { Angiogenic } \\
\text { high-throughput } \\
\text { platform }\end{array}$ & $\begin{array}{l}\text { HUVEC-VeraVec }{ }^{\top M} \text { human endothelial } \\
\text { cells }\end{array}$ & $\begin{array}{l}4.0 \mathrm{mg} / \mathrm{ml} \text { solution of } \\
\text { collagen type I }\end{array}$ & $\begin{array}{l}\text { High-throughput, perfusion rocker; } \\
\text { optimize the combination of angiogenic } \\
\text { factors }\end{array}$ & van Duinen et al., 2019 \\
\hline Angiogenic chip & $\begin{array}{l}\text { Human umbilical vein endothelial cells } \\
\text { or RFP-expressing HUVECs }\end{array}$ & $\begin{array}{l}2.5 \mathrm{mg} / \mathrm{ml} \text { solution of } \\
\text { type I collagen }\end{array}$ & $\begin{array}{l}\text { Screen for anti-angiogenic therapeutic } \\
\text { drugs }\end{array}$ & Kim et al., 2015 \\
\hline $\begin{array}{l}\text { Blood-brain barrier } \\
\text { chip (BBB chips) }\end{array}$ & $\begin{array}{l}\text { The brain endothelial cell line bEnd.3 } \\
\text { and the glial cell line C6 }\end{array}$ & Collagen IV/fibronectin & $\begin{array}{l}\text { Quantified trans-endothelial electrical } \\
\text { resistance (TEER); the permeability of } \\
\text { the blood-brain barrier was measured }\end{array}$ & van der Helm et al., 2016 \\
\hline $\begin{array}{l}\text { Cerebral vasculatures } \\
\text { chip }\end{array}$ & $\begin{array}{l}\text { Primary cultured HUVECs and human } \\
\text { astrocytes }\end{array}$ & Attachment & $\begin{array}{l}\text { Testing for chip based permeability } \\
\text { measurement of drugs }\end{array}$ & Yeon et al., 2012 \\
\hline $\begin{array}{l}\text { Tumor angiogenesis } \\
\text { chip }\end{array}$ & HUVECs and MSCs, cancer cell line & starPEG solution & $\begin{array}{l}\text { Mimic tumor angiogenesis } \\
\text { microenvironments in vivo }\end{array}$ & Bray et al., 2015 \\
\hline Wet-AMD on a Chip & $\begin{array}{l}\text { HUVECs and normal human lung } \\
\text { fibroblasts, ARPE-19 cell line }\end{array}$ & fibrinogen solution & $\begin{array}{l}\text { Modeling the pathogenesis of CNV } \\
\text { especially in terms of morphogenesis }\end{array}$ & Chung et al., 2018 \\
\hline Vessel-chips & Endothelial progenitor cells from blood & Type I rat-tail collagen & $\begin{array}{l}\text { Modeling vascular inflammation and } \\
\text { thrombosis }\end{array}$ & Mathur et al., 2019 \\
\hline $\begin{array}{l}\text { Pulmonary-arterial- } \\
\text { hypertension } \\
\text { (PAH)-on-a-chip }\end{array}$ & $\begin{array}{l}\text { ECs, SMCs, and ADCs isolated from } \\
\text { healthy human and patients with } \\
\text { idiopathic PAH (IPAH) }\end{array}$ & Type I collagen solution & $\begin{array}{l}\text { Modeling the PAH pathophysiology on } \\
\text { the device }\end{array}$ & Al-Hilal et al., 2020 \\
\hline Liver-on-a-chip & $\begin{array}{l}\text { HepG2 (from ATCC HB-8065) and } \\
\text { HUVECs (from ATCC PCS100-010) }\end{array}$ & Spheroid in suspension & $\begin{array}{l}\text { Modeling the nonalcoholic fatty liver } \\
\text { disease }\end{array}$ & Lasli et al., 2019 \\
\hline $\begin{array}{l}\text { Microvascular transport } \\
\text { system }\end{array}$ & $\begin{array}{l}\text { Human dermal microvascular } \\
\text { endothelial cells }\end{array}$ & Attachment & $\begin{array}{l}\text { Modeling the transport function of the } \\
\text { human cardiovascular system }\end{array}$ & Schimek et al., 2013 \\
\hline
\end{tabular}


growth and function of blood vessels (Bramfeldt et al., 2010; Zhang et al., 2018).

\section{Large or Small Vessels}

At present, the application of large-caliber stent vessels in clinical applications will allow good blood flow perfusion and connectivity in the short-term, although in the long-term, further embolic events will often occur due to the deposition of blood components. The function, and often the transplantation of such large-caliber blood vessels, is limited to less than $1.5 \mathrm{~cm}$ in length, which is relatively costly (Fukunishi et al., 2016). The ideal vascular graft should be able to undergo rapid vascular remodeling by promoting host cell infiltration and encourage accompanying stent degradation. The perfusion function of small-caliber blood vessels and the maintenance of fluids is much more difficult to achieve. Therefore, to reconstruct large scale blood vessels, the acellular matrix-based angiogenesis is considered as optimal method with low rate of thrombosis occurrence and well anastomosis. Compared with the vascular chip, it can be used as a more convenient technology to verify or reproduce the function of part of the blood vessels in the body to simulate vascular-related diseases. In addition, due to the advantages of the repeatability and easy expansion of the

\section{REFERENCES}

Adibfar, A., Amoabediny, G., Baghaban Eslaminejad, M., Mohamadi, J., Bagheri, F., and Zandieh Doulabi, B. (2018). VEGF delivery by smart polymeric PNIPAM nanoparticles affects both osteogenic and angiogenic capacities of human bone marrow stem cells. Mater. Sci. Eng. C Mater. Biol. Appl. 93, 790-799. doi: 10.1016/j.msec.2018.08.037

Alarçin, E., Lee, T. Y., Karuthedom, S., Mohammadi, M., Brennan, M. A., Lee, D. H., et al. (2018). Injectable shear-thinning hydrogels for delivering osteogenic and angiogenic cells and growth factors. Biomater. Sci. 6, 1604-1615. doi: 10.1039/c8bm00293b

Al-Hilal, T. A., Keshavarz, A., Kadry, H., Lahooti, B., Al-Obaida, A., Ding, Z., et al. (2020). Pulmonary-arterial-hypertension (PAH)-on-a-chip: fabrication, validation and application. Lab. Chip. 20, 3334-3345.

Andjelkovic, A. V., Stamatovic, S. M., Phillips, C. M., Martinez-Revollar, G., and Keep, R. F. (2020). Modeling blood-brain barrier pathology in cerebrovascular disease in vitro: current and future paradigms. Fluids Barriers CNS 17:44.

Assmann, A., Delfs, C., Munakata, H., Schiffer, F., Horstkotter, K., Huynh, K., et al. (2013). Acceleration of autologous in vivo recellularization of decellularized aortic conduits by fibronectin surface coating. Biomaterials 34, 6015-6026. doi: 10.1016/j.biomaterials.2013.04.037

Augustin, H. G., and Koh, G. Y. (2017). Organotypic vasculature: from descriptive heterogeneity to functional pathophysiology. Science 357:eaal2379. doi: 10 . 1126/science.aal2379

Bae, H., Puranik, A. S., Gauvin, R., Edalat, F., Carrillo-Conde, B., Peppas, N. A., et al. (2012). Building vascular networks. Sci. Transl. Med. 4:160ps123.

Baldwin, H. S. (1996). Early embryonic vascular development. Cardiovasc. Res. 31:E34-E45.

Barth, D. A., Prinz, F., Teppan, J., Jonas, K., Klec, C., and Pichler, M. (2020). LongNoncoding RNA (lncRNA) in the regulation of Hypoxia-Inducible Factor (HIF) in cancer. Noncoding RNA 6:27. doi: 10.3390/ncrna6030027

Belair, D. G., Whisler, J. A., Valdez, J., Velazquez, J., Molenda, J. A., Vickerman, V., et al. (2015). Human vascular tissue models formed from human induced pluripotent stem cell derived endothelial cells. Stem Cell Rev. Rep. 11, 511-525. doi: 10.1007/s12015-014-9549-5

Blache, U., and Ehrbar, M. (2018). Inspired by nature: hydrogels as versatile tools for vascular engineering. Adv. Wound Care (New Rochelle) 7, 232-246. doi: 10.1089/wound.2017.0760 artificial vascular chip, it offers the promise to enable commercial applications in high-throughput drug screening.

\section{AUTHOR CONTRIBUTIONS}

DZ, YL, and XR conceived of the presented idea, supervised the project, and contributed equally to the final version of the manuscript. XM, YX, and JL summarized the reference and draft the manuscript. CD helped with collected the reference. $\mathrm{XM}$ draft the table. DZ organized the figure with online free material. All authors contributed to the article and approved the submitted version.

\section{FUNDING}

All phase of this study was supported by a Key R\&D Program of Sichuan Province of China (2020YFS0102), National Natural Science Foundation of China (81700360 and 31871496), Hubei Science Fund for Distinguished Young Scholars (2019CFA091), and The China Scholarship Council (201808440462). The funders had no role in study design, data collection and analysis, decision to publish, or preparation of the manuscript.

Boden, J., Lassance-Soares, R. M., Wang, H. L., Wei, Y. T., Spiga, M. G., Adi, J., et al. (2016). Vascular regeneration in ischemic hindlimb by adeno-associated virus expressing conditionally silenced vascular endothelial growth factor. J. Am. Heart Assoc. 5:e001815.

Bogoslovsky, T., Chaudhry, A., Latour, L., Maric, D., Luby, M., Spatz, M., et al. (2010). Endothelial progenitor cells correlate with lesion volume and growth in acute stroke. Neurology 75, 2059-2062. doi: 10.1212/wnl.0b013e318200d741

Bonandrini, B., Figliuzzi, M., Papadimou, E., Morigi, M., Perico, N., Casiraghi, F., et al. (2014). Recellularization of well-preserved acellular kidney scaffold using embryonic stem cells. Tissue Eng. Part A 20, 1486-1498. doi: 10.1089/ten.tea. 2013.0269

Bonauer, A., Carmona, G., Iwasaki, M., Mione, M., Koyanagi, M., Fischer, A., et al. (2009). MicroRNA-92a controls angiogenesis and functional recovery of ischemic tissues in mice. Science 324, 1710-1713. doi: 10.1126/science.1174381

Booth, R., and Kim, H. (2012). Characterization of a microfluidic in vitro model of the blood-brain barrier ( $\mu$ BBB). Lab Chip 12, 1784-1792.

Booth, R., and Kim, H. (2014). Permeability analysis of neuroactive drugs through a dynamic microfluidic in vitro blood-brain barrier model. Ann. Biomed. Eng. 42, 2379-2391. doi: 10.1007/s10439-014-1086-5

Bramfeldt, H., Sabra, G., Centis, V., and Vermette, P. (2010). Scaffold vascularization: a challenge for three-dimensional tissue engineering. Curr. Med. Chem. 17, 3944-3967. doi: 10.2174/0929867107932 05327

Bray, L. J., Binner, M., Holzheu, A., Friedrichs, J., Freudenberg, U., Hutmacher, D. W., et al. (2015). Multi-parametric hydrogels support $3 \mathrm{D}$ in vitro bioengineered microenvironment models of tumour angiogenesis. Biomaterials 53, 609-620. doi: 10.1016/j.biomaterials.2015.02.124

Caballero Aguilar, L. M., Silva, S. M., and Moulton, S. E. (2019). Growth factor delivery: defining the next generation platforms for tissue engineering. J. Control. Release 306, 40-58. doi: 10.1016/j.jconrel.2019.05.028

Chan, B. P., and Leong, K. W. (2008). Scaffolding in tissue engineering: general approaches and tissue-specific considerations. Eur. Spine J. 17, S467-S479.

Chandra, P., and Atala, A. (2019). Engineering blood vessels and vascularized tissues: technology trends and potential clinical applications. Clin. Sci. 133, 1115-1135. doi: 10.1042/cs20180155

Chen, F. M., Zhang, M., and Wu, Z. F. (2010). Toward delivery of multiple growth factors in tissue engineering. Biomaterials 31, 6279-6308. doi: 10.1016/ j.biomaterials.2010.04.053 
Chiu, L. L. Y., and Radisic, M. (2010). Scaffolds with covalently immobilized VEGF and Angiopoietin-1 for vascularization of engineered tissues. Biomaterials 31, 226-241. doi: 10.1016/j.biomaterials.2009.09.039

Cho, H., Seo, J. H., Wong, K. H., Terasaki, Y., Park, J., Bong, K., et al. (2015). Threedimensional blood-brain barrier model for in vitro studies of neurovascular pathology. Sci. Rep. 5:15222.

Chung, M., Lee, S., Lee, B. J., Son, K., Jeon, N. L., and Kim, J. H. (2018). Wet-AMD on a chip: modeling outer blood-retinal barrier in vitro. Adv. Healthc. Mater. 7,

Chwalek, K., Tsurkan, M. V., Freudenberg, U., and Werner, C. (2014). Glycosaminoglycan-based hydrogels to modulate heterocellular communication in in vitro angiogenesis models. Sci. Rep. 4:4414.

Ciampi, O., Bonandrini, B., Derosas, M., Conti, S., Rizzo, P., Benedetti, V., et al. (2019). Engineering the vasculature of decellularized rat kidney scaffolds using human induced pluripotent stem cell-derived endothelial cells. Sci. Rep. 9:8001.

Cochrane, A., Albers, H. J., Passier, R., Mummery, C. L., Van Den Berg, A., Orlova, V. V., et al. (2019). Advanced in vitro models of vascular biology: human induced pluripotent stem cells and organ-on-chip technology. Adv. Drug Deliv. Rev. 140, 68-77. doi: 10.1016/j.addr.2018.06.007

Conway, E. M., Collen, D., and Carmeliet, P. (2001). Molecular mechanisms of blood vessel growth. Cardiovasc. Res. 49, 507-521. doi: 10.1016/s0008-6363(00) 00281-9

Dijkstra, K. K., Cattaneo, C. M., Weeber, F., Chalabi, M., Van De Haar, J., Fanchi, L. F., et al. (2018). Generation of Tumor-Reactive T Cells by Co-culture of Peripheral Blood Lymphocytes and Tumor Organoids. Cell 174, 1586.e-1598.e.

Doi, R., Tsuchiya, T., Mitsutake, N., Nishimura, S., Matsuu-Matsuyama, M., Nakazawa, Y., et al. (2017). Transplantation of bioengineered rat lungs recellularized with endothelial and adipose-derived stromal cells. Sci. Rep. 7:8447.

Du, Y., Khandekar, G., Llewellyn, J., Polacheck, W., Chen, C. S., and Wells, R. G. (2020). A bile duct-on-a-chip with organ-level functions. Hepatology 71, 1350-1363. doi: 10.1002/hep.30918

Duygu, B., Juni, R., Ottaviani, L., Bitsch, N., Wit, J. B. M., De Windt, L. J., et al. (2019). Comparison of different chemically modified inhibitors of miR-199b in vivo. Biochem. Pharmacol. 159, 106-115. doi: 10.1016/j.bcp.2018.11.013

Eilken, H. M., Diéguez-Hurtado, R., Schmidt, I., Nakayama, M., Jeong, H. W., Arf, H., et al. (2017). Pericytes regulate VEGF-induced endothelial sprouting through VEGFR1. Nat. Commun. 8:1574.

Elaimy, A. L., and Mercurio, A. M. (2018). Convergence of VEGF and YAP/TAZ signaling: implications for angiogenesis and cancer biology. Sci. Signal. 11:eaau1165. doi: $10.1126 /$ scisignal.aau1165

Enriquez-Ochoa, D., Robles-Ovalle, P., Mayolo-Deloisa, K., and Brunck, M. E. G. (2020). Immobilization of growth factors for cell therapy manufacturing. Front. Bioeng. Biotechnol. 8:620. doi: 10.3389/fbioe.2020.00620

Erbs, S., Linke, A., Schächinger, V., Assmus, B., Thiele, H., Diederich, K. W., et al. (2007). Restoration of microvascular function in the infarct-related artery by intracoronary transplantation of bone marrow progenitor cells in patients with acute myocardial infarction: the Doppler substudy of the Reinfusion of Enriched Progenitor Cells and Infarct Remodeling in Acute Myocardial Infarction (REPAIR-AMI) trial. Circulation 116, 366-374. doi: 10.1161/circulationaha.106.671545

Fernandez, C. E., Yen, R. W., Perez, S. M., Bedell, H. W., Povsic, T. J., Reichert, W. M., et al. (2016). Human vascular microphysiological system for in vitro drug screening. Sci. Rep. 6:21579.

Freeman, I., and Cohen, S. (2009). The influence of the sequential delivery of angiogenic factors from affinity-binding alginate scaffolds on vascularization. Biomaterials 30, 2122-2131. doi: 10.1016/j.biomaterials.2008.12. 057

Fukunishi, T., Best, C. A., Sugiura, T., Shoji, T., Yi, T., Udelsman, B., et al. (2016). Tissue-engineered small diameter arterial vascular grafts from cell-free nanofiber PCL/Chitosan scaffolds in a sheep model. PLoS One 11:e0158555. doi: 10.1371/journal.pone.0158555

Gilpin, A., and Yang, Y. (2017). Decellularization strategies for regenerative medicine: from processing techniques to applications. Biomed. Res. Int. 2017:9831534

Golub, J. S., Kim, Y. T., Duvall, C. L., Bellamkonda, R. V., Gupta, D., Lin, A. S., et al. (2010). Sustained VEGF delivery via PLGA nanoparticles promotes vascular growth. Am. J. Physiol. Heart Circ. Physiol. 298:H1959-H1965.
Graça, M. F. P., Miguel, S. P., Cabral, C. S. D., and Correia, I. J. (2020). Hyaluronic acid-Based wound dressings: a review. Carbohydr. Polym. 241:116364. doi: 10.1016/j.carbpol.2020.116364

Greco Song, H. H., Rumma, R. T., Ozaki, C. K., Edelman, E. R., and Chen, C. S. (2018). Vascular tissue engineering: progress. Challenges, and Clinical Promise. Cell Stem Cell 22:608. doi: 10.1016/j.stem.2018.03.014

Gridley, T. (2010). Notch Signaling in the Vasculature. Curr. Top. Dev. Biol. 92, 277-309. doi: 10.1016/S0070-2153(10)92009-7

Gui, L. Q., Muto, A., Chan, S. A., Breuer, C. K., and Niklason, L. E. (2009). Development of decellularized human umbilical arteries as small-diameter vascular grafts. Tissue Eng. Part A 15, 2665-2676. doi: 10.1089/ten.tea.2008. 0526

Hao, W., Han, J., Chu, Y., Huang, L., Zhuang, Y., Sun, J., et al. (2018). Collagen/Heparin Bi-affinity multilayer modified collagen scaffolds for controlled bfgf release to improve angiogenesis in Vivo. Macromol. Biosci. 18:e1800086.

Hayashi, H., and Kume, T. (2008). Foxc transcription factors directly regulate Dll4 and Hey2 expression by interacting with the VEGF-Notch signaling pathways in endothelial cells. PLoS One 3:e2401. doi: 10.1371/journal.pone.0002401

Hoganson, D. M., O'doherty, E. M., Owens, G. E., Harilal, D. O., Goldman, S. M., Bowley, C. M., et al. (2010). The retention of extracellular matrix proteins and angiogenic and mitogenic cytokines in a decellularized porcine dermis. Biomaterials 31, 6730-6737. doi: 10.1016/j.biomaterials.2010.05.019

Hong, H., and Tian, X. Y. (2020). The role of macrophages in vascular repair and regeneration after ischemic injury. Int. J. Mol. Sci. 21:6328. doi: 10.3390/ ijms 21176328

Hou, J., Wang, L., Wu, Q., Zheng, G., Long, H., Wu, H., et al. (2018). Long noncoding RNA H19 upregulates vascular endothelial growth factor A to enhance mesenchymal stem cells survival and angiogenic capacity by inhibiting miR-199a-5p. Stem Cell Res. Ther. 9:109.

Hu, S., Huang, M., Li, Z., Jia, F., Ghosh, Z., Lijkwan, M. A., et al. (2010). MicroRNA210 as a novel therapy for treatment of ischemic heart disease. Circulation 122 , S124-S131.

Huang, C. K., Kafert-Kasting, S., and Thum, T. (2020). Preclinical and clinical development of noncoding RNA therapeutics for cardiovascular disease. Circ. Res. 126, 663-678. doi: 10.1161/circresaha.119.315856

Hur, J., Yoon, C. H., Kim, H. S., Choi, J. H., Kang, H. J., Hwang, K. K., et al. (2004). Characterization of two types of endothelial progenitor cells and their different contributions to neovasculogenesis. Arterioscler. Thromb. Vasc. Biol. 24, 288-293. doi: 10.1161/01.atv.0000114236.77009.06

Ingram, D. A., Mead, L. E., Moore, D. B., Woodard, W., Fenoglio, A., and Yoder, M. C. (2005). Vessel wall-derived endothelial cells rapidly proliferate because they contain a complete hierarchy of endothelial progenitor cells. Blood 105, 2783-2786. doi: 10.1182/blood-2004-08-3057

Iwaguro, H., Yamaguchi, J., Kalka, C., Murasawa, S., Masuda, H., Hayashi, S., et al. (2002). Endothelial progenitor cell vascular endothelial growth factor gene transfer for vascular regeneration. Circulation 105, 732-738. doi: 10.1161/ hc0602.103673

Jeevanantham, V., Butler, M., Saad, A., Abdel-Latif, A., Zuba-Surma, E. K., and Dawn, B. (2012). Adult bone marrow cell therapy improves survival and induces long-term improvement in cardiac parameters: a systematic review and meta-analysis. Circulation 126, 551-568. doi: 10.1161/circulationaha.111. 086074

Jeon, J. S., Bersini, S., Whisler, J. A., Chen, M. B., Dubini, G., Charest, J. L., et al. (2014). Generation of 3D functional microvascular networks with human mesenchymal stem cells in microfluidic systems. Integr. Biol. (Camb) 6, 555563. doi: $10.1039 / \mathrm{c} 3 \mathrm{ib} 40267 \mathrm{c}$

Kant, R. J., and Coulombe, K. L. K. (2018). Integrated approaches to spatiotemporally directing angiogenesis in host and engineered tissues. Acta Biomater. 69, 42-62. doi: 10.1016/j.actbio.2018.01.017

Kaushal, S., Amiel, G. E., Guleserian, K. J., Shapira, O. M., Perry, T., Sutherland, F. W., et al. (2001). Functional small-diameter neovessels created using endothelial progenitor cells expanded ex vivo. Nat. Med. 7, 1035-1040. doi: 10.1038/nm0901-1035

Ketchedjian, A., Jones, A. L., Krueger, P., Robinson, E., Crouch, K., Wolfinbarger, L., et al. (2005). Recellularization of decellularized allograft scaffolds in ovine great vessel reconstructions. Ann. Thorac. Surg. 79, 888-896. doi: 10.1016/j. athoracsur.2004.09.033 
Khetan, S., and Burdick, J. A. (2010). Patterning network structure to spatially control cellular remodeling and stem cell fate within 3-dimensional hydrogels. Biomaterials 31, 8228-8234. doi: 10.1016/j.biomaterials.2010.07.035

Kim, C., Kasuya, J., Jeon, J., Chung, S., and Kamm, R. D. (2015). A quantitative microfluidic angiogenesis screen for studying anti-angiogenic therapeutic drugs. Lab Chip 15, 301-310. doi: 10.1039/c4lc00866a

Kim, Y. H., Hu, H., Guevara-Gallardo, S., Lam, M. T., Fong, S. Y., and Wang, R. A. (2008). Artery and vein size is balanced by Notch and ephrin B2/EphB4 during angiogenesis. Development 135, 3755-3764. doi: 10.1242/dev.022475

Langhans, S. A. (2018). Three-dimensional in vitro cell culture models in drug discovery and drug repositioning. Front. Pharmacol. 9:6. doi: 10.3389/fphar. 2018.00006

Lasli, S., Kim, H. J., Lee, K., Suurmond, C. E., Goudie, M., Bandaru, P., et al. (2019). A human liver-on-a-chip platform for modeling nonalcoholic fatty liver disease. Adv. Biosyst. 3:e1900104.

Li, B., Zhou, Y., Chen, J., Wang, T., Li, Z., Fu, Y., et al. (2020). Long noncoding RNA H19 contributes to wound healing of diabetic foot ulcer. J. Mol. Endocrinol. 19.R-0242.R.

Li, D. Y., Busch, A., Jin, H., Chernogubova, E., Pelisek, J., Karlsson, J., et al. (2018). H19 induces abdominal aortic aneurysm development and progression. Circulation 138, 1551-1568.

Li, L., Wang, M., Mei, Z., Cao, W., Yang, Y., Wang, Y., et al. (2017). IncRNAs HIF1A-AS2 facilitates the up-regulation of HIF- $1 \alpha$ by sponging to miR$153-3$ p, whereby promoting angiogenesis in HUVECs in hypoxia. Biomed. Pharmacother. 96, 165-172. doi: 10.1016/j.biopha.2017.09.113

Li, S., Sengupta, D., and Chien, S. (2014). Vascular tissue engineering: from in vitro to in situ. Wiley Interdiscip. Rev. Syst. Biol. Med. 6, 61-76. doi: 10.1002/wsbm. 1246

Lin, D. S. Y., Guo, F., and Zhang, B. (2019). Modeling organ-specific vasculature with organ-on-a-chip devices. Nanotechnology 30:024002. doi: 10.1088/13616528/aae7de

Liu, G., Fang, Z., Yuan, M., Li, W., Yang, Y., Jiang, M., et al. (2017). Biodegradable carriers for delivery of VEGF plasmid DNA for the treatment of critical limb ischemia. Front. Pharmacol. 8:528. doi: 10.3389/fphar.2017.00528

Long, F. Q., Su, Q. J., Zhou, J. X., Wang, D. S., Li, P. X., Zeng, C. S., et al. (2018). LncRNA SNHG12 ameliorates brain microvascular endothelial cell injury by targeting miR-199a. Neural Regen. Res. 13, 1919-1926. doi: 10.4103/1673-5374. 238717

Lui, K. O., Zangi, L., and Chien, K. R. (2014). Cardiovascular regenerative therapeutics via synthetic paracrine factor modified mRNA. Stem Cell Res. 13, 693-704. doi: 10.1016/j.scr.2014.06.007

Materne, E. M., Maschmeyer, I., Lorenz, A. K., Horland, R., Schimek, K. M., Busek, M., et al. (2015). The multi-organ chip-a microfluidic platform for long-term multi-tissue coculture. J. Vis. Exp. e52526.

Mathur, T., Singh, K. A., Nk, R. P., Tsai, S. H., Hein, T. W., Gaharwar, A. K., et al. (2019). Organ-on-chips made of blood: endothelial progenitor cells from blood reconstitute vascular thromboinflammation in vessel-chips. Lab Chip 19, 2500-2511. doi: 10.1039/c9lc00469f

Mazza, G., Rombouts, K., Hall, A. R., Urbani, L., Luong, T. V., Al-Akkad, W., et al. (2015). Decellularized human liver as a natural 3D-scaffold for liver bioengineering and transplantation. Sci. Rep. 5:13079.

Miao, C., Cao, H., Zhang, Y., Guo, X., Wang, Z., and Wang, J. (2018). LncRNA DIGIT accelerates tube formation of vascular endothelial cells by sponging miR-134. Int. Heart J. 59, 1086-1095. doi: 10.1536/ihj.17-290

Narita, Y., Kagami, H., Matsunuma, H., Murase, Y., Ueda, M., and Ueda, Y. (2008). Decellularized ureter for tissue-engineered small-caliber vascular graft. J. Artif. Organs 11, 91-99. doi: 10.1007/s10047-008-0407-6

Nohata, N., Hanazawa, T., Enokida, H., and Seki, N. (2012). microRNA-1/133a and microRNA-206/133b clusters: dysregulation and functional roles in human cancers. Oncotarget 3, 9-21. doi: 10.18632/oncotarget.424

Oduk, Y., Zhu, W., Kannappan, R., Zhao, M., Borovjagin, A. V., Oparil, S., et al. (2018). VEGF nanoparticles repair the heart after myocardial infarction. Am. J. Physiol. Heart Circ. Physiol. 314, H278-H284.

Omorphos, N. P., Gao, C., Tan, S. S., and Sangha, M. S. (2021). Understanding angiogenesis and the role of angiogenic growth factors in the vascularisation of engineered tissues. Mol. Biol. Rep. 48, 941-950. doi: 10.1007/s11033-02006108-9
Ott, H. C., Clippinger, B., Conrad, C., Schuetz, C., Pomerantseva, I., Ikonomou, L., et al. (2010). Regeneration and orthotopic transplantation of a bioartificial lung. Nat. Med. 16, 927-933. doi: 10.1038/nm.2193

Ozerdem, U., and Stallcup, W. B. (2003). Early contribution of pericytes to angiogenic sprouting and tube formation. Angiogenesis 6, 241-249. doi: 10. 1023/b:agen.0000021401.58039.a9

Peattie, R. A., Rieke, E. R., Hewett, E. M., Fisher, R. J., Shu, X. Z., and Prestwich, G. D. (2006). Dual growth factor-induced angiogenesis in vivo using hyaluronan hydrogel implants. Biomaterials 27, 1868-1875. doi: 10.1016/j. biomaterials.2005.09.035

Pike, D. B., Cai, S. S., Pomraning, K. R., Firpo, M. A., Fisher, R. J., Shu, X. Z., et al. (2006). Heparin-regulated release of growth factors in vitro and angiogenic response in vivo to implanted hyaluronan hydrogels containing VEGF and bFGF. Biomaterials 27, 5242-5251. doi: 10.1016/j.biomaterials.2006.05.018

Portillo-Lara, R., Spencer, A. R., Walker, B. W., Shirzaei Sani, E., and Annabi, N. (2019). Biomimetic cardiovascular platforms for in vitro disease modeling and therapeutic validation. Biomaterials 198, 78-94. doi: 10.1016/j.biomaterials. 2018.08.010

Potente, M., Gerhardt, H., and Carmeliet, P. (2011). Basic and therapeutic aspects of angiogenesis. Cell 146, 873-887. doi: 10.1016/j.cell.2011.08.039

Rajantie, I., Ilmonen, M., Alminaite, A., Ozerdem, U., Alitalo, K., and Salven, P. (2004). Adult bone marrow-derived cells recruited during angiogenesis comprise precursors for periendothelial vascular mural cells. Blood 104, $2084-$ 2086. doi: 10.1182/blood-2004-01-0336

Raval, Z., and Losordo, D. W. (2013). Cell therapy of peripheral arterial disease: from experimental findings to clinical trials. Circ. Res. 112, 1288-1302. doi: 10.1161/circresaha.113.300565

Rehman, J., Traktuev, D., Li, J. L., Merfeld-Clauss, S., Temm-Grove, C. J., Bovenkerk, J. E., et al. (2004). Secretion of angiogenic and antiapoptotic factors by human adipose stromal cells. Circulation 109, 1292-1298. doi: 10.1161/01. cir.0000121425.42966.f1

Rhodes, J. M., and Simons, M. (2007). The extracellular matrix and blood vessel formation: not just a scaffold. J. Cell. Mol. Med. 11, 176-205. doi: 10.1111/j. 1582-4934.2007.00031.x

Ribas, J., Sadeghi, H., Manbachi, A., Leijten, J., Brinegar, K., Zhang, Y. S., et al. (2016). Cardiovascular organ-on-a-chip platforms for drug discovery and development. Appl. In Vitro Toxicol. 2, 82-96. doi: 10.1089/aivt.2016.0002

Samatoshenkov, I. V., Salafutdinov, I. I., Zuravleva, M. N., Kostennikov, A. A., Rizvanov, A. A., and Chelyshev, Y. A. (2020). Adenoviral vector delivery of vegf, angiogenin, and gdnf genes promotes angiogenesis in ischemic skeletal muscle. BioNanoScience 10, 540-547. doi: 10.1007/s12668-019-00688-y

Sarker, M. D., Naghieh, S., Sharma, N. K., and Chen, X. (2018). 3D biofabrication of vascular networks for tissue regeneration: a report on recent advances. J. Pharm. Anal. 8, 277-296. doi: 10.1016/j.jpha.2018.08.005

Sarker, M. D., Naghieh, S., Sharma, N. K., Ning, L., and Chen, X. (2019). Bioprinting of vascularized tissue scaffolds: influence of biopolymer. cells,growth factors, and gene delivery. J. Healthc. Eng. 2019:9156921.

Savoji, H., Mohammadi, M. H., Rafatian, N., Toroghi, M. K., Wang, E. Y., Zhao, Y., et al. (2019). Cardiovascular disease models: a game changing paradigm in drug discovery and screening. Biomaterials 198, 3-26. doi: 10.1016/j.biomaterials. 2018.09.036

Schimek, K., Busek, M., Brincker, S., Groth, B., Hoffmann, S., Lauster, R., et al. (2013). Integrating biological vasculature into a multi-organ-chip microsystem. Lab Chip 13, 3588-3598. doi: 10.1039/c3lc50217a

Schmidt, J. J., Rowley, J., and Kong, H. J. (2008). Hydrogels used for cell-based drug delivery. J. Biomed. Mater. Res. A 87, 1113-1122. doi: 10.1002/jbm.a.32287

Schwarz, E. R., Speakman, M. T., Patterson, M., Hale, S. S., Isner, J. M. Kedes, L. H., et al. (2000). Evaluation of the effects of intramyocardial injection of DNA expressing vascular endothelial growth factor (VEGF) in a myocardial infarction model in the rat-angiogenesis and angioma formation. J. Am. Coll. Cardiol. 35, 1323-1330. doi: 10.1016/s0735-1097(00) 00522-2

Shamloo, A., Sarmadi, M., Aghababaie, Z., and Vossoughi, M. (2018). Accelerated full-thickness wound healing via sustained bFGF delivery based on a PVA/chitosan/gelatin hydrogel incorporating PCL microspheres. Int. J. Pharm. 537, 278-289. doi: 10.1016/j.ijpharm.2017.12.045 
Shen, Y. I., Cho, H., Papa, A. E., Burke, J. A., Chan, X. Y., Duh, E. J., et al. (2016). Engineered human vascularized constructs accelerate diabetic wound healing. Biomaterials 102, 107-119. doi: 10.1016/j.biomaterials.2016.06.009

Smith, H. K., Omura, S., Vital, S. A., Becker, F., Senchenkova, E. Y., Kaur, G., et al. (2018). Metallothionein I as a direct link between therapeutic hematopoietic stem/progenitor cells and cerebral protection in stroke. FASEB J. 32, 2381-2394. doi: 10.1096/fj.201700746r

Sui, S., Sun, L., Zhang, W., Li, J., Han, J., Zheng, J., et al. (2020). LncRNA MEG8 attenuates cerebral ischemia after ischemic stroke through targeting miR-130a-5p/VEGFA signaling. Cell. Mol. Neurobiol. [Epub ahead of print].

Tayalia, P., and Mooney, D. J. (2009). Controlled growth factor delivery for tissue engineering. Adv. Mater. 21, 3269-3285. doi: 10.1002/adma.200900241

Tetzlaff, F., and Fischer, A. (2018). Control of blood vessel formation by notch signaling. Adv. Exp. Med. Biol. 1066, 319-338. doi: 10.1007/978-3-319-895123_16

Theocharis, A. D., Skandalis, S. S., Gialeli, C., and Karamanos, N. K. (2016). Extracellular matrix structure. Adv. Drug Deliv. Rev. 97, 4-27.

Thottappillil, N., and Nair, P. D. (2015). Scaffolds in vascular regeneration: current status. Vasc. Health Risk Manag. 11, 79-91. doi: 10.2147/vhrm.s50536

Uhrin, P. (2019). "Cellular and molecular mechanisms of vasculogenesis, angiogenesis, and lymphangiogenesis," in Fundamentals of Vascular Biology, ed. M. Geiger (Cham: Springer International Publishing), 131-143. doi: 10.1007/ 978-3-030-12270-6_7

Uygun, B. E., Soto-Gutierrez, A., Yagi, H., Izamis, M. L., Guzzardi, M. A., Shulman, C., et al. (2010). Organ reengineering through development of a transplantable recellularized liver graft using decellularized liver matrix. Nat. Med. 16:814U120.

van der Helm, M. W., Van Der Meer, A. D., Eijkel, J. C., Van Den Berg, A., and Segerink, L. I. (2016). Microfluidic organ-on-chip technology for bloodbrain barrier research. Tissue Barriers 4:e1142493. doi: 10.1080/21688370.2016. 1142493

van Duinen, V., Van Den Heuvel, A., Trietsch, S. J., Lanz, H. L., Van Gils, J. M., Van Zonneveld, A. J., et al. (2017). 96 perfusable blood vessels to study vascular permeability in vitro. Sci. Rep. 7:18071.

van Duinen, V., Zhu, D., Ramakers, C., Van Zonneveld, A. J., Vulto, P., and Hankemeier, T. (2019). Perfused 3D angiogenic sprouting in a high-throughput in vitro platform. Angiogenesis 22, 157-165. doi: 10.1007/s10456-0189647-0

Wang, D., Tai, P. W. L., and Gao, G. (2019). Adeno-associated virus vector as a platform for gene therapy delivery. Nat. Rev. Drug Discov. 18, 358-378. doi: 10.1038/s41573-019-0012-9

Wang, Z., Wang, R., Wang, K., and Liu, X. (2018). Upregulated long noncoding RNA Snhg1 promotes the angiogenesis of brain microvascular endothelial cells after oxygen-glucose deprivation treatment by targeting miR-199a. Can. J. Physiol. Pharmacol. 96, 909-915. doi: 10.1139/cjpp-2018-0107

Wang, Z., Wang, Z., Lu, W. W., Zhen, W., Yang, D., and Peng, S. (2017). Novel biomaterial strategies for controlled growth factor delivery for biomedical applications. NPG Asia Mater. 9:e435. doi: 10.1038/am.2017.171

Yang, C., Han, B., Cao, C., Yang, D., Qu, X., and Wang, X. (2018). An injectable double-network hydrogel for the co-culture of vascular endothelial cells and bone marrow mesenchymal stem cells for simultaneously enhancing vascularization and osteogenesis. J. Mater. Chem. B 6, 7811-7821. doi: 10.1039/ c8tb02244e

Yasotharan, S., Pinto, S., Sled, J. G., Bolz, S.-S., and Günther, A. (2015). Artery-ona-chip platform for automated, multimodal assessment of cerebral blood vessel structure and function. Lab Chip 15, 2660-2669. doi: 10.1039/c5lc00021a

Yeon, J. H., Na, D., Choi, K., Ryu, S. W., Choi, C., and Park, J. K. (2012). Reliable permeability assay system in a microfluidic device mimicking cerebral vasculatures. Biomed. Microdevices 14, 1141-1148. doi: 10.1007/s10544-0129680-5

Yow, K. H., Ingram, J., Korossis, S. A., Ingham, E., and Homer-Vanniasinkam, S. (2006). Tissue engineering of vascular conduits. Br. J. Surg. 93, 652-661. doi: 10.1002/bjs.5343

Zampetaki, A., Willeit, P., Burr, S., Yin, X., Langley, S. R., Kiechl, S., et al. (2016). Angiogenic microRNAs linked to incidence and progression of diabetic retinopathy in type 1 diabetes. Diabetes 65, 216-227.

Zangi, L., Lui, K. O., Von Gise, A., Ma, Q., Ebina, W., Ptaszek, L. M., et al. (2013). Modified mRNA directs the fate of heart progenitor cells and induces vascular regeneration after myocardial infarction. Na. Biotechnol. 31, 898-907. doi: $10.1038 /$ nbt.2682

Zhang, B., Korolj, A., Lai, B. F. L., and Radisic, M. (2018). Advances in organon-a-chip engineering. Nat. Rev. Mater. 3, 257-278. doi: 10.1038/s41578-0180034-7

Zhang, W. J., Liu, W., Cui, L., and Cao, Y. L. (2007). Tissue engineering of blood vessel. J. Cell. Mol. Med. 11, 945-957.

Zhang, Y. S., Aleman, J., Shin, S. R., Kilic, T., Kim, D., Mousavi Shaegh, S. A., et al. (2017). Multisensor-integrated organs-on-chips platform for automated and continual in situ monitoring of organoid behaviors. Proc. Natl. Acad. Sci. U.S.A. 114, E2293-E2302.

Zhao, L., Johnson, T., and Liu, D. (2017). Therapeutic angiogenesis of adiposederived stem cells for ischemic diseases. Stem Cell Res. Ther. 8:125.

Zhao, Z., Sun, W., Guo, Z., Zhang, J., Yu, H., and Liu, B. (2020). Mechanisms of lncRNA/microRNA interactions in angiogenesis. Life Sci. 254:116900. doi: 10.1016/j.lfs.2019.116900

Zhou, Z. W., Zheng, L. J., Ren, X., Li, A. P., and Zhou, W. S. (2019). LncRNA NEAT1 facilitates survival and angiogenesis in oxygen-glucose deprivation (OGD)-induced brain microvascular endothelial cells (BMECs) via targeting miR-377 and upregulating SIRT1, VEGFA, and BCL-XL. Brain Res. 1707, 90-98. doi: 10.1016/j.brainres.2018.10.031

Conflict of Interest: The authors declare that the research was conducted in the absence of any commercial or financial relationships that could be construed as a potential conflict of interest.

Copyright (c) 2021 Meng, Xing, Li, Deng, Li, Ren and Zhang. This is an open-access article distributed under the terms of the Creative Commons Attribution License (CC BY). The use, distribution or reproduction in other forums is permitted, provided the original author(s) and the copyright owner(s) are credited and that the original publication in this journal is cited, in accordance with accepted academic practice. No use, distribution or reproduction is permitted which does not comply with these terms. 